\title{
Normal course of events amongst Swedish soccer players: an 8-year follow-up study
}

\author{
J. Ekstrand, MD, PhD, H. Roos, MD and H. Tropp, MD, PhD \\ The Sports Medicine Unit, Department of Orthopaedic Surgery, University Hospital, Linköping, Sweden
}

In this study 180 male soccer players entered into a prospective study of injuries in 1980 . They were examined again in 1988. The aim of the present study was to evaluate the course of events during their active period. The study was carried out using a questionnaire. The importance of major injuries was evaluated. Hospital records were scrutinized and 179 of 180 (99 per cent) were included in the evaluation.

Keywords: Soccer, natural course, questionnaire

\section{Introduction}

Association football, or soccer, is the most common sport in the world, being played in 150 countries $^{1}$. Soccer was introduced into Sweden in 1880 and is now the sport with the largest number of players ${ }^{2}$.

Advantages of being physically active have been emphasized in recent years, mainly because of the beneficial effects on the cardiovascular system ${ }^{3}$. The more people are active, however, the more injuries occur $^{4}$. It has been proposed that 50 per cent to 60 per cent of all sports injuries in Europe are due tó soccer ${ }^{5}$. We have previously evaluated not only the incidence of soccer injuries but also the possibility of their prevention ${ }^{2,6}$. Several other epidemiological surveys from other countries have outlined the incidence and types of injury in soccer ${ }^{2,7-13}$. It is interesting to know to what extent the injury affects soccer play, but until now we have not not known the natural history of the soccer player.

The aim of this research survey was to discover the outcome of events in a population of soccer players over a longer period of time. The main topics for evaluation were the length of active participation in soccer, the number and importance of major injuries, and the reasons for giving up the sport.

\section{Method and material}

In 1980 Ekstrand et al. studied 180 players (age $24.6 \pm 4.6$, range 17-38 years, age distribution as in

Address for correspondence: Assistant Prof Jan Ekstrand, Sports Clinic, Department of Orthopaedics, University Hospital, S-581 85 Linköpnig, Sweden

(C) 1990 Butterworth-Heinemann Ltd 0306-4179/90/020117-03
Figure 1) from a male senior soccer division, with a regard to past injuries ${ }^{9}$. They were also followed during the season and a prospective evaluation of injuries was done. The best 15 players from each of 12 teams in a Division IV league (Norra Östergötland) were selected. The Swedish senior male league system is described in Table 1 . These players were at the medium level. The system has been changed since 1980 but the structure was still similar in 1988 .

All 180 players were contacted by mail and asked to answer a questionnaire concerning:

- which teams they had joined

- in which division they had played

- if they had given up soccer

- reasons for any changes

- major injuries, with emphasis on knee, ankle, and groin.

An injury was defined as any injury sustained while playing soccer, severe enough to require

Table 1. The Swedish senior male league system, 1980

\begin{tabular}{lrc}
\hline Div & League & Total no. of teams \\
\hline I & 1 & 12 \\
II & 2 & 24 \\
III & 12 & 144 \\
IV & 36 & 432 \\
V & 64 & 700 \\
VI & 161 & 1900 \\
Total approx. & & 3000 \\
\hline
\end{tabular}

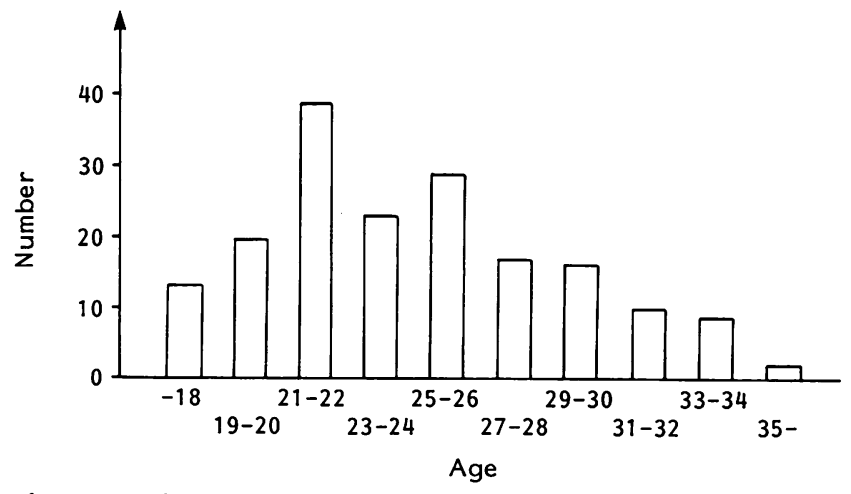

Figure 1. The age distribution of the material, 1980 
absence from practice or games for more than two weeks.

To obtain detailed information, the inquiry was supplemented by examination of records kept at local hospitals. This was done for every knee injury since the players could not as a rule describe the type of trauma in an adequate way.

The questionnaire was sent to the players in January 1988. This meant that the players could state if they had quit after the 1987 season, which was the last season for reported injuries. The period of retrospective evaluation totalled eight years.

\section{Results}

The percentage replying was initially 65 per cent, but after a reminder by mail or telephone 179 of the 180 (99 per cent) responded. One player did not consent to the use of his data. It became clear that players gave up soccer at different years according to their age. We defined two groups; (A) men 25 years or less in $1980(n=110)$, and (B) men older than $25(n=68)$, at the beginning of the study.

In Figure 2 the relative fall-off each year for the two groups is presented.

None of the players in B had ever played at a higher level than the 3rd division. In group A two players reached the 1st division, one of them being a member of the Swedish national team at the time of evaluation. Three players in group (A) had reached the 2nd division.

The players had been faithful to their teams. Seventy-two per cent of the players in both groups (A) and (B) never left the team to which they belonged in 1980 . This means that most of the players only changed level if their team moved up or down in the league system.

After eight years (1980-1988) 62 of 178 (35 per cent) were still active ( 49 of $110=45$ per cent in group (A), 13 of $68=19$ per cent in group (B)); the rest had given up soccer during this period (55 per cent in group (A), 81 per cent in group (B)). The mean relative fall-off each year was $12.3 \pm 4.3$ per cent for the total group $(9.5 \pm 4.3$ in group $(A), \pm 7.5$ per cent in group (B)). The reasons for giving up soccer are shown in Table 2. A total of 38 per cent (group (A) 41 per cent group (B) 35 per cent) gave up soccer for

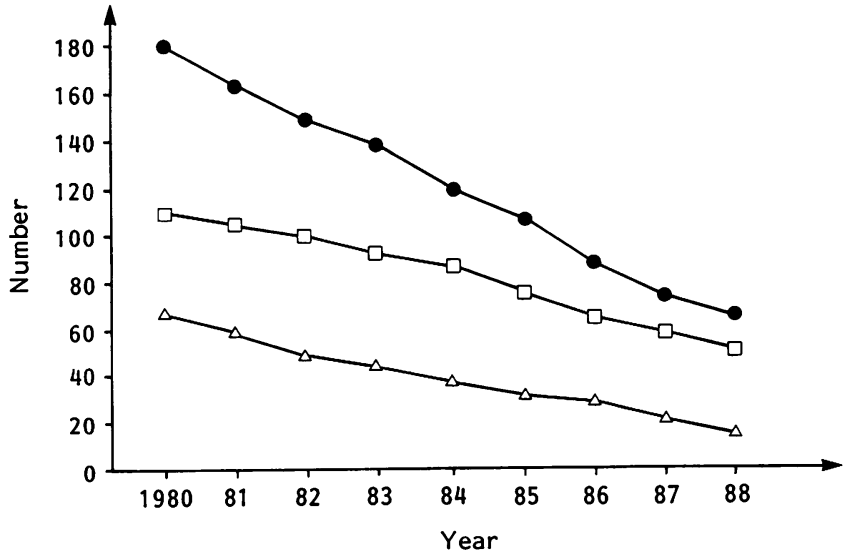

Figure 2. The number of active players $1980-1988 . \bullet=$ total group $\square=$ group $A(>25$ years) $\Delta=$ group $B(>25$ years)
Table 2. Reasons for giving up soccer

\begin{tabular}{|c|c|c|c|}
\hline Reason & $\begin{array}{c}\text { Total } \\
n=178\end{array}$ & $\begin{array}{l}\text { Group } A \\
n=110\end{array}$ & $\begin{array}{c}\text { Group } B \\
n=68\end{array}$ \\
\hline Injury & $25(22 \%)$ & $13(21 \%)$ & 12 (22\%) \\
\hline Age & $16(14 \%)$ & $3(5 \%)$ & $13(24 \%)$ \\
\hline $\begin{array}{l}\text { Lack of } \\
\text { motivation }\end{array}$ & $18(16 \%)$ & $12(20 \%)$ & $6(11 \%)$ \\
\hline $\begin{array}{l}\text { Social } \\
\text { reasons }\end{array}$ & $44(38 \%)$ & $25(41 \%)$ & $19(35 \%)$ \\
\hline Other & $13(11 \%)$ & $8(13 \%)$ & $5(9 \%)$ \\
\hline Total & 116 & 61 & 55 \\
\hline
\end{tabular}

social reasons (work, family etc.) A total of 14 per cent put the blame on age, but a difference was noted between the two groups; 24 per cent in group (B) versus 5 per cent in group (A). Lack of motivation was referred to by 16 per cent. A total of 25 of 116 (22 per cent) of the players had given up soccer because of injury (21 per cent in group (A), 22 per cent in group (B)).

Knee and ankle injuries were dominant (Table 3) in both groups. Absence from play was higher for knee than for ankle injuries (Table 4). The knee injuries are listed in Table 5. Only the primary injuries are listed. Associated or secondary meniscal injuries are not included. Of the six players with anterior cruciate

Table 3. The total numbers of reported injuries, divided into subgroups

\begin{tabular}{lcc}
\hline Type of injury & $\begin{array}{c}\text { Number of } \\
\text { players }\end{array}$ & $\begin{array}{c}\text { Number of } \\
\text { injuries }\end{array}$ \\
\hline Group A & 35 & 45 \\
Knee & 51 & 65 \\
Ankle & & 8 \\
Groin & & 1 \\
Fracture & & 2 \\
Achilles $\quad$ & 3 \\
$\quad$ rupture & & 9 \\
tendinitis & & 17 \\
Guscle strain & & 13 \\
Kneup B & 14 & 1 \\
Ankle & 11 & 3 \\
Groin & & -6 \\
Fracture & & 4 \\
Achilles & & \\
$\quad$ rupture & & \\
tendinitis & & \\
\hline
\end{tabular}

Table 4. Absence from play due to knee and ankle injuries within the two groups

\begin{tabular}{lcc}
\hline & Absence (months) \\
\cline { 2 - 3 } & Total & Perinjury \\
\hline Group A & & \\
Knee & 167 & 3.7 \\
Ankle & 82 & 1.3 \\
Group B & & \\
Knee & 53 & 3.1 \\
Ankle & 14 & 1.1 \\
\hline
\end{tabular}


Table 5. The three different types of knee injury found

\begin{tabular}{lcc}
\hline \multicolumn{1}{c}{ Knee injuries } & Number & Operated \\
\hline Anterior cruciate ligament & 10 & 6 \\
Posterior cruciate ligament & 3 & 1 \\
Medial collateral ligament & 18 & 3 \\
\hline
\end{tabular}

Only the primary diagnosis is presented. Associated or secondary meniscal injuries are not shown

ligament injury treated by acute repair, four were still active at the end of the study. None of the players treated conservatively was still active.

Among those who quit because of injury, knee injuries were the dominant cause: 70 per cent for both (A) and (B). Other injuries were the occasional ankle, back, hip, muscular, tendon, and skeletal injuries.

\section{Discussion}

Several epidemiological surveys have outlined the incidence of injury in soccer ${ }^{2,5,8-15}$. Different studies are not always comparable, however, due to variation in definitions of injury and different types of population. The type of soccer play (age, amateur or professional, male or female, national or international etc.) affect the standard of pitches, medical service, exposition and injury rate. We have previously reported data regarding soccer injuries in Swedish male amateur players ${ }^{2,8}$. When studying the significance of soccer injuries it was important to know the normal course of events for soccer players with regard to major injuries, years of active play, reasons for giving up soccer etc.

The high response percentage was probably due to the fact that the players had been examined in 1980 and interviewed by the same orthopaedic surgeon connected with this enquiry.

The players at this medium level were very faithful to their teams. None of the older and only two of the younger group reached top level.

This study is based on a prospective study in 1980 . The questionnaire method is retrospective and may therefore be incomplete. There is also a risk that minor injuries are forgotten.

The most important factor concerning the design of the study was that the selection of players, based on soccer ability done in 1980 and reviewed in 1988 therefore gave the natural course of events for the players is true. In a pure retrospective study concerning players still active, one will by definition miss all those players who suffered injuries that prevented their playing. A total of 65 per cent of the players gave up soccer during the eight year period, a mean fall-off of 12 per cent each year with 19 per cent among the older and 10 per cent among the younger players. It was found that injuries are responsible for 22 per cent of those quitting. The majority of the players gave up soccer for social reasons, which may reflect the non-elite level at which they played. Other figures may well have been found amongst top-level and professional soccer players where ambitions are higher. The most important injuries are those affecting the knee and the ankle. They were responsible for, on average, five and two weeks of absence from play respectively. Nine per cent of all players had suffered knee injuries that prevented their playing. Those with anterior cruciate ligament injuries were not able to continue playing unless they were operated upon either with suture and reinforcement or reconstruction of the anterior cruciate ligament.

It has been shown that a preventive programme can be successful in decreasing the incidence of injuries ${ }^{2}$. Ankle sprains can be prevented ${ }^{6}$ by functional training, or bracing. The biggest problem seems to be knee injuries. These injuries affect not only soccer activities but also the social life of the players, including work. They disturb many activities of daily life and increase medical costs etc. At present there is no evidence to suggest that preventative measures help concerning knee ligament injuries. The literature even suggests an increased risk for knee injuries when a supportive brace is applied ${ }^{16}$.

\section{References}

1 FIFA. Laws of the game and universal guide for references with USSF supplement. International Soccer Association (FIFA) English Ed. 1984.

2 Ekstrand, J. Soccer injuries and their prevention. Linköping University Medical Dissertations No. 130, Linköping, Sweden, 1982

3 Andersson, G. The importance of exercise for sick leave and perceived health. Linköping University Medical Dissertations No. 243, Linköping, Sweden 1987

4 Andersson, G., Malmgren, S. and Ekstrand, J. Occurrence of athletic injuries in voluntary participatns in a 1-year extensive exercise campaign Int $J$ Sports Med 1986, 7, 222-225

5 Franke, K. Traumatologie des Sports. Berlin, VEB Verlag, 1977

6 Tropp, H., Askling, C. and Gillquist, J. Prevention of ankle sprains. Am J Sports Med 1985, 13, 259-262

7 Albert, M. Descriptive three year data study of outdoor and indoor professional soccer injuries Athletic Training 1983, 18, 218-220

8 Biener, K. Fussballsportunfälle Schweiz Zeitung Sportmed 1967, 15, 121-130

9 Ekstrand, J. and Gillquist, J. The frequency of muscle tightness and injuries in soccer players Am J Sports Med 1982, 2, 75-78

10 Keller, C.S., Noyes, F.R. and Bruncher, C.R. The medical aspectsof soccer injury epidemiology $A m J$ Sports Med 1987, 15, 230-237

11 McMaster, W.C., and Walter, M. Injuries in soccer $A m$ J Sports Med 1987, 6, 354-357

12 Nilsson, S. and Rooas, A. Soccer injuries in adolescents Am J Sport Med 1978, 6, 358-361

13 Pardon, E.T. Lower extremities are thesite of most soccer injuries Phys Sports Med 1977, 5 (6), 43-48

14 Ekstrand, J., Gillquist, J., Möller, M. et al. Incidence of soccer injuries and their relation to training and team success Am J Sports Med 1983, 11, 63-67

15 Sullivan, J.A., Gross, R.H., Grana, W.A. et al. Evaluation of injuries in youth soccer Am J Sports Med 1980, 8, 325-327

16 Teitz, C.C., Hermanson, B.K., Kronmal, R.A. et al. Evaluation of the use of braces to prevent injury to the knee in collegiate football players J Bone Joint Surg 1987, 69A: 2-9 